\title{
Measuring Risks of Confirming Warehouse Financing from the Third Party Logistics Perspective
}

\author{
Zhixin Wang and Yue Wang * \\ School of Business, University of Jinan, Jinan 250002, China; 20172120795@mail.ujn.edu.cn \\ * Correspondence: se_wangy@ujn.edu.cn
}

Received: 18 October 2019; Accepted: 17 November 2019; Published: 21 November 2019

\begin{abstract}
Confirmation warehouse financing is an important model in supply chain finance. This type of financing has special characteristics due to the existence of the reverse repurchase link, and it increases the risk commitment of the core enterprise at a certain level. Previous research on supply chain financial risk mostly settled in 'all-industry, multi-model', ignoring the special risks of single mode. To supplement the vacancies in the current research, the special risks of supply chain finance should be identified under a single model. On this basis, a measurement index system for confirmation warehouse financing risk is created. The article uses a Back Propagation (BP) neural network to build a Third Party Logistics (3PL) perspective of the risk measurement model for confirmation warehouse financing. The said network is combined with the 24 sets of actual cases from ZY Logistics. MATLAB is used to train the sample data. Results show that the absolute errors $-0.042998,-0.011102,0.020514$ and 0.039448 - between the training value and the predicted value are smaller than the preset error value. Among the 24 cases, high-risk businesses reached $41.7 \%$, whereas low-risk businesses only accounted for $29.2 \%$. The $\mathrm{ZY}$ enterprise confirms that warehouse financial business risk is high, and this situation should be revised. Research shows that the risk measurement indicator system has good risk prediction ability. This study establishes and verifies the rationality of the risk measurement index system and provides a reliable reference for 3PL risk aversion in supply chain finance.
\end{abstract}

Keywords: supply chain finance; Third Party Logistics; Back Propagation neural network; risk measurement

\section{Introduction}

In China, small- and medium-sized enterprises (SMEs) have become an important part of its national economy and are the most important component of the modern market economy. According to the National Small and Medium Enterprises Development Report released by the State Administration for Industry and Commerce in 2018, the report states that as of the end of 2017, the number of SMEs included in the directory of China's small and micro enterprises (SMEs) has reached 73.281 million by the end of 2017. Among them, 23.278 million enterprises, accounted for $82.5 \%$ of the total number of enterprises, where as there are 50.03 million individual industrial and commercial households, accounting for $80.9 \%$ of the total number of individual industrial and commercial households. The vast majority of SMEs are the basic forces for promoting employment, improving livelihood, stabilizing society, developing the economy, and promoting innovation. SMEs are the largest and most dynamic enterprise group in the urban economy, yet money is the blood of business development. However, problems in financing restrict the development of SMEs.

Supply chain finance is a new body combining industry and finance that effectively solves the financing difficulties of SMEs and greatly improves the coordination of supply chains. The model for confirming warehouse financing is an operation mode of supply chain finance, which enables SMEs to obtain financing from banks with the guarantee and influence of core enterprises. As a result, 
the model reduces the financing costs of enterprises, alleviates the pressure on corporate funds, increases product sales, and brings new profit margins for banks and third-party logistics (3PL) to achieve a multi-win. In addition, a retailer's inventory pressure is largely reduced, and the promotion and sales of goods are enhanced due to the existence of a reverse repo channel in the confirming warehouse financing model. As core companies in the confirming warehouse financing model are concerned about the funding problems of downstream retailers, guarantee loans for retailers increase the risks for supply chain finance. As a result, several SMEs resort to information hiding and information fraud and pledge shortages to obtain loans. Each node company seeks to maximize its interests as a direct participant in supply chain finance. This scenario can lead to lack of cooperation, information asymmetry, and untimely feedback among enterprises. These conditions hinder the normal procedures of confirming warehouse financing. Introducing 3PL as a coordination and regulator of supply chain finance circumvents various financing risks. Therefore, exploring the key factors influencing the risk of confirmation warehouse financing, constructing an effective early warning model, and reducing the probability of risk are of practical significance to promote the stable development of supply chain finance.

\section{Literature Review}

The hot topic of supply chain finance has been highly valued by the business community and academia. The research content mainly includes the definition of the concept of supply chain finance and its model and risk.

Local and foreign scholars have carried out a fierce debate with regard to the definition of the core concepts of supply chain finance. In summary, these scholars have mainly conducted research from different angles. Santomero (2000) proposed that supply chain finance is a financing method that combines financial and supply chain services. This definition of supply chain finance is simple and straightforward, but it only captures the two parties involved in the supply chain and does not take into account the role of financing companies [1]. Allen N. Berger et al. (2004) initially defined supply chain finance on the basis of an in-depth analysis of the financing model of SMEs [2]. Lero Klapper (2005) conducted a comprehensive survey of inventory pledge models in supply chain finance and analyzed their operational processes and functions [3]. Other scholars, such as Jüttner (2005) and Guillen $(2007)[4,5]$, argued that the real definition of supply chain finance is combining the production and financing links of enterprises and incorporating them into the management model of unified management in the supply chain management framework. Gomm (2010) [6] and Mangiaracina (2016) [7] elucidated the supply chain using the best strategy to promote the efficiency of capital utilization and greatly improve coordination. Supply chain finance can promote the relationship between upstream and downstream enterprises and core enterprises, rationally allocate capital flows, and accelerate the operation of funds among enterprises [8,9]. Many scholars have contended that supply chain finance is a derivative of financial institutions for expanding business and that it can effectively reduce financing costs $[10,11]$. The emergence of supply chain finance has rationally allocated and managed the capital chain and effectively improved operational efficiency [12] and optimized management channels in supply chain finance [13].

Confirming warehouse financing is one of the modes of operation in supply chain finance. Scholars have provided various views about the research on the operation mode of supply chain finance. For example, Albert (1945), Friedman (1942) [14], Raymand (1948), Dunham (1949) [15], and Burman (1966) [16] focused on the inventory pledge model and supply receivables in supply chain finance and investigated the account model in detail; in these works, the authors pointed out the business models, legal guarantees, and warehousing methods under two modes of operation and compared the differences between the two models, thus laying the foundation for the study on the two financial models. Guerrisi (2001) [17] explored the technology of capital transfer in supply chain finance from e-commerce and proposed a network-based electronic money transfer transaction method and applied it to the global trade supply chain [18,19]. Erik Hofmann (2009) [20] mainly viewed 
supply chain finance from the perspective of 3PL companies. The author also put forward that the quantity, value, and nature of an enterprise's inventory and the service level of a logistics enterprise influence the income model of supply chain finance to a certain extent. Schafer and Henry (2014) [21] discussed the conflicts related to working capital among members of the supply chain on the basis of an idealized automotive supply chain network. Furthermore, Zhong and Sun et al. (2016) [22] proposed an inventory financing pricing model that maximizes the cash flow of 3PL enterprises when the default rate of SMEs is affected by pledge price.

Every financial product has its risks, and the research on the risks of supply chain finance is endless. Coulter and Onumah (2002) [23] pointed out that the market price fluctuation in pledge loans includes certain risks. Schwartz, Gibson, and Hilliard et al. (2000) [24] surveyed the prices of financial products involved in supply chain finance and sought an appropriate price for reducing the risk. Chen Jiajuan (2010) [25] mainly examined risks using the warehouse receipt pledge model. He and Tang (2012) [26] observed the operation mode of supply chain finance and proposed risk prevention measures. Pellegrino and Roberta (2018) [27] carried out an optimization study on services related to supply chain finance and proposed a risk-sharing approach for reducing the cost and improving the stability of supply chain finance. Liu and Li et al. (2018) categorized the risks of supply chain finance into several subanalyses and carried out a dialysis study of hydrological division on the basis of big data environment [28]. Hu and Ansell (2007) [29] conducted an in-depth analysis of credit risk in supply chain finance and introduced novel macroeconomic variables and internal financial indicators as references. Chu (2017) [30] considered the various participants in supply chain finance and used simulation techniques to quantify risks. Fangzhi Fan et al. (2017) [31] used quantitative indicators as their focus of research and used Analytic Hierarchy Process to evaluate risks. Gu and Jiang (2017) [32] established an early warning model for credit risk on the basis of the logistic regression model. Hamadi and Abdelmoula (2010) [33] established a three-layer BP neural network as an early warning model on the basis of the data of financing companies.

The research on the risks of supply chain finance has several shortcomings despite the numerous articles from local and foreign scholars for the following reasons. First, most scholars focused on core enterprises or financial institutions as the research perspective and did not consider the characteristics of stratifying the role of supply chain finance; such deficiency can lead to the subjectivity of the identified risks. Second, several scholars established corresponding risk assessment index systems on the basis of risk conditions without conducting empirical research on system feasibility. Third, the identification of risks cannot be generalized and should be handled separately because each financing model has distinct characteristics and differences. Considering these three points, the current study selects 3PL as the research perspective, elucidates the vicious competitive relationships among participating entities, and selects a financing model with a wide applicability in the market. Dissecting the risk characteristics of this model can lay the foundation for future index systems and models of risk measurement.

\section{Operational Mode and Risk Identification}

\subsection{Operational Mode of Confirming Warehouse Financing}

Confirming warehouse financing is a relatively complicated operation mode of supply chain finance as it requires the participation of suppliers, financing enterprise, banks, and 3PL enterprises. It is a financing loan model that uses bank acceptance bills as settlement instruments. In confirming warehouse financing, goods undergo a repurchase process, which greatly reduces the risks of financial institutions and 3PL companies. The confirmation of financing in supply chain finance is a fixed pattern. Currently, no unified business flow chart exists in the academic community. According to the definition and operation mode of the confirmation warehouse financing, this study draws a flow chart of the confirmation warehouse financing business. This figure can provide a basis for risk identification below. Figure 1 illustrates the business model of confirming warehouse financing. 


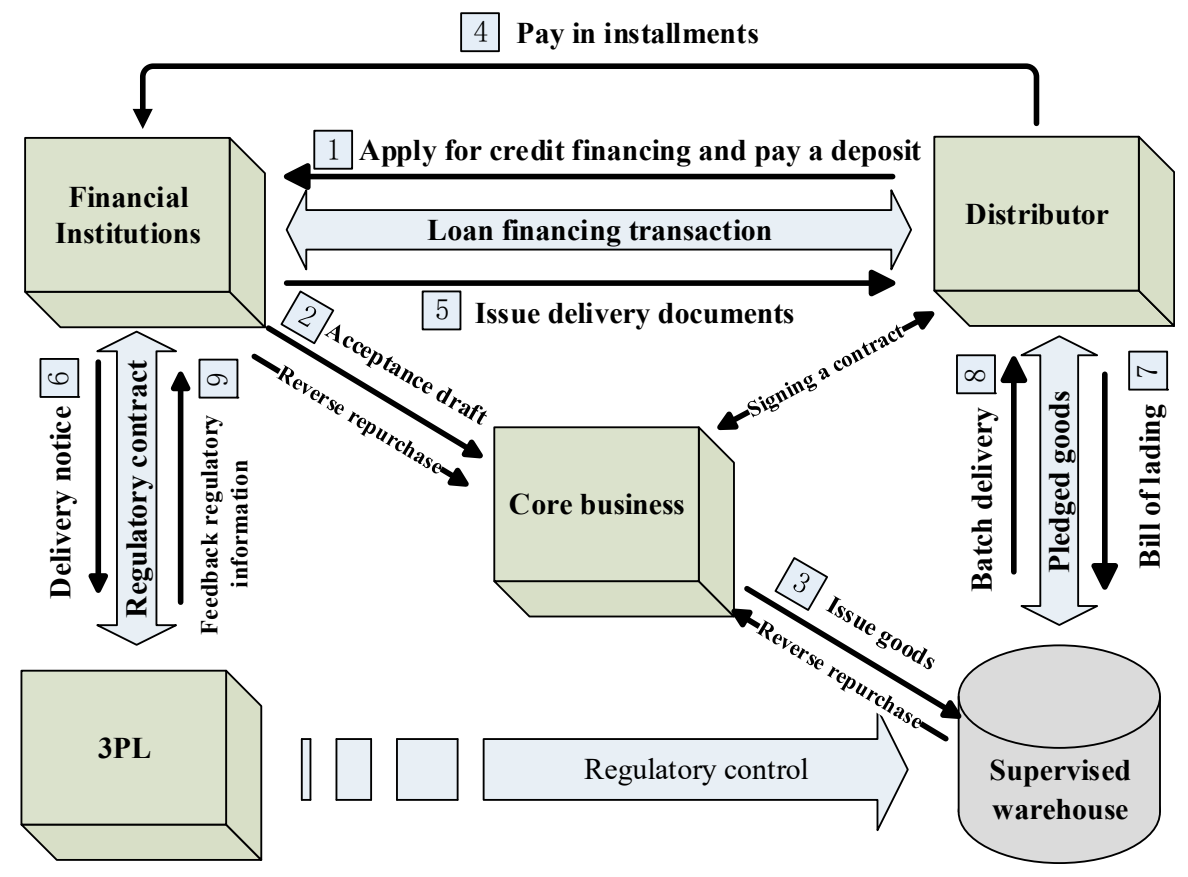

Figure 1. Flowchart of operation mode of confirming warehouse financing.

The basic operation flow is detailed as follows:

1. A dealer applies for credit financing from a bank and pays the deposit to purchase goods.

2. The bank issues an acceptance bill to the supplier on the basis of the application.

3. After receiving the confirmation of the acceptance draft, the supplier releases the goods to the 3PL-supervised warehouse.

4. The dealer repays the loan in one lump sum or in batches according to the contract.

5. After the bank receives the repayment, the bank provides the dealer with a delivery voucher.

6. The bank simultaneously issues a notice of delivery to the 3PL.

7. The dealer holds the goods, and the one-way 3PL picks up the goods.

8. The 3PL delivers the goods in batches according to the bill of lading.

9. If the dealer is unable to repay the loan, then the bank initiates a notification to the supplier, which reverses the repo.

\subsection{Establishing the Risk Measurement Index System}

With gradual changes and increased competition in the market environment, the risks of supply chain finance are constantly changing. In addition, the advent of the Internet and big data eras has hindered the adaptation of the traditional measurement indicator system to the current market environment in terms of the risk of supply chain finance. Bandaly et al. used operational methods and financial instruments to comprehensively manage the risk of supply chain finance [34]. Li and $\mathrm{Wu}$ (2008) analyzed risk on the basis of the entire process of supply chain finance and divided risk into order realization process risk, environmental risk, information system risk, and downstream vendor default risk [35]. Although the risk classification is realistic, it ignores the effects of selecting a pledge on the risk of supply chain finance. He Minghao and Qian Wenbin (2010) also investigated the risk of supply chain finance and divided it into collateral risk originating from the financing enterprise and risk of supply chain finance According to the participants in the supply chain; however, the study did not consider other financial institutions [36]. Yuan and Tang (2014) divided the risk of supply chain finance into 23 secondary indicators of eight first-level indicators, but such subdivision did not comprehensively classify the risk of supply chain finance [37]. Li and Wang et al. [38] identified and classified the financial risks of listed companies in the supply chain environment. Furthermore, 
Wei Song, Jia Mao, and Wei Li (2014) classified the risks of supply chain finance according to the main body of the supply chain. The risks of supply chain finance are divided into those faced by logistics enterprises and by financial institutions [39]. This classification ignores the importance of the risks of financing enterprises and has certain limitations in terms of evaluating the risks of supply chain finance.

The current study refers to a large number of related articles with reference to the views previously put forward by scholars. Thus, this study analyzes the risk characteristics of confirming warehouse financing and conducts in-depth analysis of the operation mode of confirming warehouse financing to identify the risks of such operation mode. From the 3PL perspective, this study establishes the risks of confirming warehouse financing on the basis of four aspects, namely, pledge risk, credit risk of financing enterprises, operation and internal management risk, and contractual legal risk. The four types can fully summarize the risk of confirming warehouse financing from the 3PL perspective and compensate for the shortcomings of the previous risk measurement index system. Moreover, the results can provide a good reference for logistics enterprises in the current market environment for carrying out supply chain finance. We conducted a preliminary selection of the indicators of the risks of confirming warehouse financing from the 3PL perspective. The indicator system results in 4 first-level indicators and 21 second-level indicators, which provide the statistical description of the first-level indicators.

1. Pledge risk (W): Price stability (W1), Legality (W2), Insurance situation (W3), Liquidity (W4), Attribute (W5).

2. Credit risk of financing companies (N): Performance ability (N1), Continuing ability (N2), Profitability (N3), Solvency (N4), Stable inventory (N5).

3. Internal management risk (P): Pledge assessment risk (P1), Regulatory system normative (P2), Inventory risk warning (P3), Quality employee (P4), Operational risk (P5), Organizational rationality $(\mathrm{P} 6)$.

4. Contract legal risk (R): Contract standardization (R1), Contractual liability risk (R2), Legal policy risk (R3), 3PL too much responsibility (R4), Order processing accuracy (R5).

Table 1 presents the preliminary establishment of the model of the index system for risk measurement.

Table 1. Index system for measuring the risks of confirming warehouse financing from the Third Party Logistics (3PL) perspective.

\begin{tabular}{|c|c|c|c|}
\hline & Construct & Item & Sources \\
\hline \multirow{4}{*}{$\begin{array}{l}\text { The risk of property insurance financing } \\
\text { under the perspective of } 3 P L\end{array}$} & Pledge risk (W) & $\begin{array}{c}\text { Price stability (W1) } \\
\text { Legality (W2) } \\
\text { Insurance situation (W3) } \\
\text { Liquidity (W4) } \\
\text { Attribute (W5) }\end{array}$ & {$[33,35,37]$} \\
\hline & Credit risk of financing companies $(\mathrm{N})$ & $\begin{array}{l}\text { Performance ability (N1) } \\
\text { Continuing ability (N2) } \\
\text { Profitability (N3) } \\
\text { Solvency (N4) } \\
\text { Stable inventory (N5) }\end{array}$ & {$[32,33,37]$} \\
\hline & Internal management risk $(\mathrm{P})$ & $\begin{array}{l}\text { Pledge assessment risk (P1) } \\
\text { Regulatory system normative (P2) } \\
\text { Inventory risk warning (P3) } \\
\text { Quality employee (P4) } \\
\text { Operational risk (P5) } \\
\text { Organizational rationality (P6) }\end{array}$ & {$[31,32,39]$} \\
\hline & Contract legal risk(R) & $\begin{array}{c}\text { Contract standardization (R1) } \\
\text { Contractual liability risk (R2) } \\
\text { Legal policy risk (R3) } \\
\text { 3PL too much responsibility (R4) } \\
\text { Order processing accuracy (R5) }\end{array}$ & {$[33,36,38]$} \\
\hline
\end{tabular}




\subsection{Screening of Risk Measurement Indicators}

Through the explanation of each indicator, we can easily conclude that the number of selected indicators is extremely large. In addition, the correlation between indicators causes difficulty in determining the existence of multiple collinearity among them. Therefore, the indicators should be tested to improve their reliability and representativeness through scientific screening.

\section{Questionnaire Design and Data Collection}

This study collected data and screens indicators by distributing questionnaires to professionals in the field. The questionnaire was accordingly designed to measure the risks of confirming warehouse financing from the 3PL perspective. The questionnaire uses five-level Likert-type scales to assign scores to the importance of the secondary indicators of logistical risk. The scale assigns importance as follows: $5=$ very important, $4=$ fairly important, $3=$ important, $2=$ less important, and $1=$ not important. The study selected three survey objects, namely, 3PL logistics enterprises engaged in supply chain finance, experts and scholars on supply chain finance, and financial institutions such as banks that provide supply chain finance. Data collection was performed in three phases for a total of four months. In the first stage, the items designed by the questionnaire were randomly disrupted and sent to more than 20 managers from the company for pre-test. According to the feedback from the participants, the members of the group revised and optimised the questionnaire in accordance to the feedback of participants. In the second stage, a questionnaire was sent to 40 students in the MBA class for experimental research. Based on the results of the confirmatory factor analysis, the questionnaire items were revised and adjusted to eventually form a formal questionnaire. In the third stage, a formal questionnaire was issued to the respondents. A total of 400 questionnaires were distributed, and 294 of them were returned. Further screening identified 288 valid questionnaires with recovery and effectivity rates of $73.5 \%$ and $72 \%$, respectively.

\section{Statistics of Respondents}

As shown in Table 2, respondents to the questionnaire were relatively balanced in terms of gender. This feature balances the judgment of risk expectations between men and women. The age class of the respondents is widely distributed. The largest age group is that between 18 and 25 years old, which accounts for $39.58 \%$ of the total number of respondents. This phenomenon is due to the late development of supply chain finance business in China. The majority of people under this line of business are college and graduate students aged between 18 and 25 years old. Chinese students are college graduates around the age of 21 , and they are knowledgeable with supply chain finance-related professions. After working in the company for two to three years, these students can become grassroots managers. According to the level of education, respondents with a bachelor's degree or above account for $93.74 \%$ of the total sample. Therefore, the respondents are highly educated and have sufficient professional knowledge and awareness of risk management. Respondents with a master's degree or above account for $53.65 \%$ of the total sample. Based on the respondents' title, grassroots managers account for $44.79 \%$ of the total sample. The age of grassroots managers is mostly concentrated in the 18-25 and 26-30 age ranges, which differ from the age of campus students. In summary, the overall level of education is remarkably high. Hence, evaluating the financing risk of confirming warehouse financing is of good professional quality, and the evaluation results are scientific. 
Table 2. Descriptive statistics of respondents.

\begin{tabular}{cccc}
\hline Construct & Item & Statistics & Percentage \\
\hline \multirow{2}{*}{ Respondent gender } & Male & 147 & $51.04 \%$ \\
& Female & 141 & $48.96 \%$ \\
\multirow{2}{*}{ Respondent age } & $18-25$ & 114 & $39.58 \%$ \\
& $26-30$ & 60 & $20.83 \%$ \\
& $31-40$ & 71 & $24.48 \%$ \\
& $41-50$ & 28 & $9.9 \%$ \\
Respondents' qualifications & $51-60$ & 6 & $3.13 \%$ \\
& $60 \leq$ & 9 & $2.08 \%$ \\
& High school diploma & 3 & $1.04 \%$ \\
& Specialist qualifications & 15 & $5.21 \%$ \\
& Bachelor's degree & 115 & $40.1 \%$ \\
Respondent's job attribution & Master's degree & 123 & $42.71 \%$ \\
& PhD and above & 32 & $10.94 \%$ \\
& Financial Institutions & 101 & $35.07 \%$ \\
& 3PL & 102 & $35.42 \%$ \\
Respondents' working age & Research institute & 85 & $29.51 \%$ \\
& $1-3$ years & 65 & $22.57 \%$ \\
& $3-5$ years & 135 & $46.87 \%$ \\
& 5-10 years & 66 & $22.92 \%$ \\
& $10 \leq$ & 22 & $7.64 \%$ \\
& Senior management & 46 & $15.97 \%$ \\
Respondent's title & Middle management & 99 & $34.37 \%$ \\
& Grassroots management & 129 & $44.79 \%$ \\
& General staff & 14 & $4.86 \%$ \\
\hline
\end{tabular}

\section{Screening Indicators}

This study employed reliability, validity, and principal component analyses to screen the primary indicators selected. The study preliminarily established the 3PL perspective of the index system for measuring the risks of confirming warehouse financing using 21 items, which were divided into four dimensions. However, the data of the four dimensions were analyzed separately. Table 3 provides the results of the analyses.

Table 3. Reliability statistics (Cronbach's $\alpha$ ).

\begin{tabular}{|c|c|c|c|c|}
\hline Construct & Item & CITC & Cronbach's Alpha & Cronbach $\alpha$ \\
\hline \multirow{5}{*}{ Pledge risk $(\mathrm{W})$} & W1 & 0.647 & 0.637 & \multirow{5}{*}{0.736} \\
\hline & W2 & 0.505 & 0.619 & \\
\hline & W3 & 0.395 & 0.773 & \\
\hline & W4 & 0.51 & 0.808 & \\
\hline & W5 & 0.322 & 0.707 & \\
\hline \multirow{5}{*}{ Credit risk of financing companies $(\mathrm{N})$} & N1 & 0.481 & 0.766 & \multirow{5}{*}{0.851} \\
\hline & $\mathrm{N} 2$ & 0.5 & 0.858 & \\
\hline & N3 & 0.498 & 0.764 & \\
\hline & N4 & 0.49 & 0.864 & \\
\hline & N5 & 0.201 & 0.745 & \\
\hline \multirow{6}{*}{ Internal management risk $(\mathrm{P})$} & P1 & 0.714 & 0.664 & \multirow{6}{*}{0.794} \\
\hline & P2 & 0.688 & 0.644 & \\
\hline & P3 & 0.79 & 0.636 & \\
\hline & P4 & 0.364 & 0.676 & \\
\hline & P5 & 0.855 & 0.656 & \\
\hline & P6 & 0.614 & 0.663 & \\
\hline \multirow{5}{*}{ Contract legal risk $(\mathrm{R})$} & R1 & 0.556 & 0.697 & \multirow{5}{*}{0.793} \\
\hline & R2 & 0.557 & 0.607 & \\
\hline & R3 & 0.557 & 0.612 & \\
\hline & R4 & 0.655 & 0.641 & \\
\hline & R5 & 0.572 & 0.766 & \\
\hline
\end{tabular}


The table shows that the Cronbach's $\alpha$ values of W, N, P and R are greater than 0.7. Thus, the four sets of research data have high reliability. The corrected item-total correlation (CITC) value is an expression of the relevance of the indicator [40]. When the CITC value is less than 0.4, the correlation between the indicator and the research question is weak [41]. In this case, the verified indicator should be deleted. The CITC values for W3 $=0.395<0.400$, W $5=0.322<0.400$. Thus, the correlation between this item and the remainder of the items is weak and can thus be corrected or omitted. The adjusted group $\mathrm{W}$ index was tested. The Cronbach's $\alpha$ was 0.841 , which was a significant improvement compared with the previous one. The CITC values for N5 $=0.201<0.400$. Delete indicator N5. After deletion, a significant improvement in the Cronbach's $\alpha(0.867)$ was observed. The CITC values for $\mathrm{P} 4=0.364<0.400$. Thus, the correlation between this item and the remainder of the items was weak and can thus be corrected or omitted. The adjusted group P index was tested, and the Cronbach's $\alpha$ was 0.813 , which was a significant improvement compared with the previous one. Through reliability testing, the adjustment index of confirming warehouse financing insurance was revised, and the modified index was further analysed through validity and factor analyses. Table 4 presents the results of the analyses.

Table 4. Kaiser Meyer Olkin (KMO) value and Bartlett's sphericity test.

\begin{tabular}{ccccc}
\hline Construct & KMO & $\chi^{\mathbf{2}}$ & Df & $\mathbf{P}$ \\
\hline W & 0.749 & 98.126 & 3 & 0 \\
N & 0.738 & 167.379 & 6 & 0 \\
P & 0.815 & 254.191 & 10 & 0 \\
R & 0.784 & 208.119 & 10 & 0 \\
\hline
\end{tabular}

Results show that the Kaiser Meyer Olkin (KMO) values of the indicators are greater than 0.6, which indicates the validity of the indicators. The data can then be used for principal component analysis. The data were tested by Bartlett's sphericity test $(p<0.05)$, the results of which indicated that the study data are suitable for principal component analysis. Table 5 provides the results.

Table 5. Principal Component Analysis.

\begin{tabular}{lcccc}
\hline \multirow{2}{*}{ Item } & \multicolumn{3}{c}{ Factor Loading } & \multirow{2}{*}{ Commonality } \\
\cline { 2 - 4 } & Component 1 & Component 2 & Component 3 & \\
\hline W1 & 0.81 & -0.343 & $* *$ & 0.775 \\
W2 & 0.821 & -0.268 & $* *$ & 0.746 \\
W4 & 0.72 & 0.693 & $* *$ & 0.998 \\
\hline N1 & 0.715 & 0.561 & 0.338 & 0.941 \\
N2 & 0.767 & 0.269 & -0.539 & 0.951 \\
N3 & 0.78 & -0.311 & 0.348 & 0.826 \\
N4 & 0.752 & -0.486 & -0.132 & 0.819 \\
\hline P1 & 0.625 & 0.494 & 0.448 & 0.836 \\
P2 & 0.696 & 0.399 & 0.139 & 0.663 \\
P3 & 0.697 & -0.615 & -0.004 & 0.864 \\
P5 & 0.658 & -0.658 & 0.033 & 0.866 \\
P6 & 0.649 & 0.424 & -0.609 & 0.971 \\
\hline R1 & 0.801 & -0.227 & -0.157 & 0.717 \\
R2 & 0.788 & -0.194 & -0.228 & 0.711 \\
R3 & 0.761 & 0.043 & -0.252 & 0.645 \\
R4 & 0.678 & -0.12 & 0.721 & 0.994 \\
R5 & 0.331 & 0.289 & 0.02 & 0.578 \\
\hline
\end{tabular}

Note: “*** means that the indicator does not have a principal Component 3. 
Table 5 shows that the cumulative variance interpretation rate of the principal component analysis is higher than $60 \%$; thus, the main content of each variable can be extracted well. In addition, the commonality of each variable is higher than 0.4 , which indicates that the correlation between variables is satisfactory and can explain most risk information. In summary, the indicator system has positive structural properties. The factor loading for R5 is less than 0.4 , which implies that the accuracy of order processing has a weak impact on contractual legal risk in supply chain finance and that its correlation with other indicators is poor. Thus, the indicator should be excluded.

Through reliability, validity, and factor analyses of the indicators in the four dimensions, we find that many risk factors of the initially established risk measurement index system are characterized by low reliability and low correlation. Thus, we removed five indicators, namely, W3, W5, N5, P4, and R5, and reclassified the risk measurement indicators that meet the standards. According to the previously established 3PL perspective of the index system for measuring the risks of confirming warehouse financing, risk was still divided into four dimensions, which included 4 first-level indicators and 16 second-level indicators. Table 6 presents the new indicator system.

Table 6. New model of the index system for measuring risks of confirming warehouse financing from the 3PL perspective.

\begin{tabular}{|c|c|c|}
\hline & Construct & Item \\
\hline \multirow{4}{*}{$\begin{array}{c}\text { The risk of property insurance financing } \\
\text { under the perspective of } 3 \mathrm{PL}\end{array}$} & Pledge risk (NW) & $\begin{array}{l}\text { Price stability (NW1) } \\
\text { Legality (NW2) } \\
\text { Liquidity (NW3) }\end{array}$ \\
\hline & $\begin{array}{l}\text { Credit risk of financing } \\
\text { companies }(\mathrm{NN})\end{array}$ & $\begin{array}{l}\text { Performance ability (NN1) } \\
\text { Continuing ability (NN2) } \\
\text { Profitability (NN3) } \\
\text { Solvency (NN4) }\end{array}$ \\
\hline & $\begin{array}{l}\text { Internal management } \\
\text { risk }(\mathrm{NP})\end{array}$ & $\begin{array}{c}\text { Pledge assessment risk (NP1) } \\
\text { Regulatory system normative (NP2) } \\
\text { Inventory risk warning (NP3) } \\
\text { Operational risk (NP4) } \\
\text { Organizational rationality (NP5) }\end{array}$ \\
\hline & Contract legal risk (NR) & $\begin{array}{c}\text { Contract standardization (NR1) } \\
\text { Contractual liability risk (NR2) } \\
\text { Legal policy risk (NR3) } \\
\text { 3PL too much responsibility (NR4) }\end{array}$ \\
\hline
\end{tabular}

\section{Establishing the Risk Measurement Model of the BP Neural Network}

\subsection{Establishing the Topology of the BP Neural Network}

Designing the topology of the BP neural network mainly includes two aspects, namely, input and output layers and a hidden layer. In the case of neural networks, neuronal nodes at the same level are independent of one another and lack a function transfer relationship. Interrelationships are observed among neuronal nodes with a drive for transfer function. A general BP neural network includes an input layer, an output layer, and no more than one hidden layer.

1. Number of Neurons in the Input Layer

The number of input neurons is generally determined according to the problem to be solved. In addition, the number of variables to be studied determines the number of neurons in the input layer. In this work, the problem to be studied is the risk measurement of confirming warehouse financing from the 3PL perspective. The neurons in the input layer are set as the risk measurement indicators. The index system for risk measurement contains 4 first-level indicators and 16 second-level indicators. 
All secondary indicators are set as input neuronal nodes such that the number of neurons in the input layer $(m)$ is 16 .

\section{Number of Neurons in the Hidden Layer}

In the BP neural network, a continuous function can be approximated by a single hidden layer in the BP neural network for any closed interval. Therefore, a three-layer neural network can perform arbitrary $\mathrm{m}$-dimensional to n-dimensional mapping. The BP neural network selected in this paper only contains one hidden layer, and the number of nodes in the hidden layer (i) is nonunified. In general, an excessive number of nodes in the hidden layer will lead to a long learning time. However, the error is not necessarily optimal. Various BP neural network models contain an optimal number of nodes in the hidden layer. The following equation is used to select the number of optimal nodes in the hidden layer:

$$
m_{i}=\sqrt{m+n}+\theta
$$

where $(m)$ is the number of neurons in the input layer, $(n)$ is the number of neurons in the output layer, and $(\theta)$ is a constant between [1-10].

\section{Number of Neurons in the Output Layer}

The number of nodes in the output layer of the BP neural network is dependent on the form of the evaluation result of the measurement model. In the risk measurement model, the final output pertains to the risk level of the finance business. To describe the risk level of supply chain finance, the output is divided into three levels, which are represented as $3=$ high risk, $2=$ medium risk, and $1=$ low risk.

Figure 2 depicts the BP neural network model established in this work.

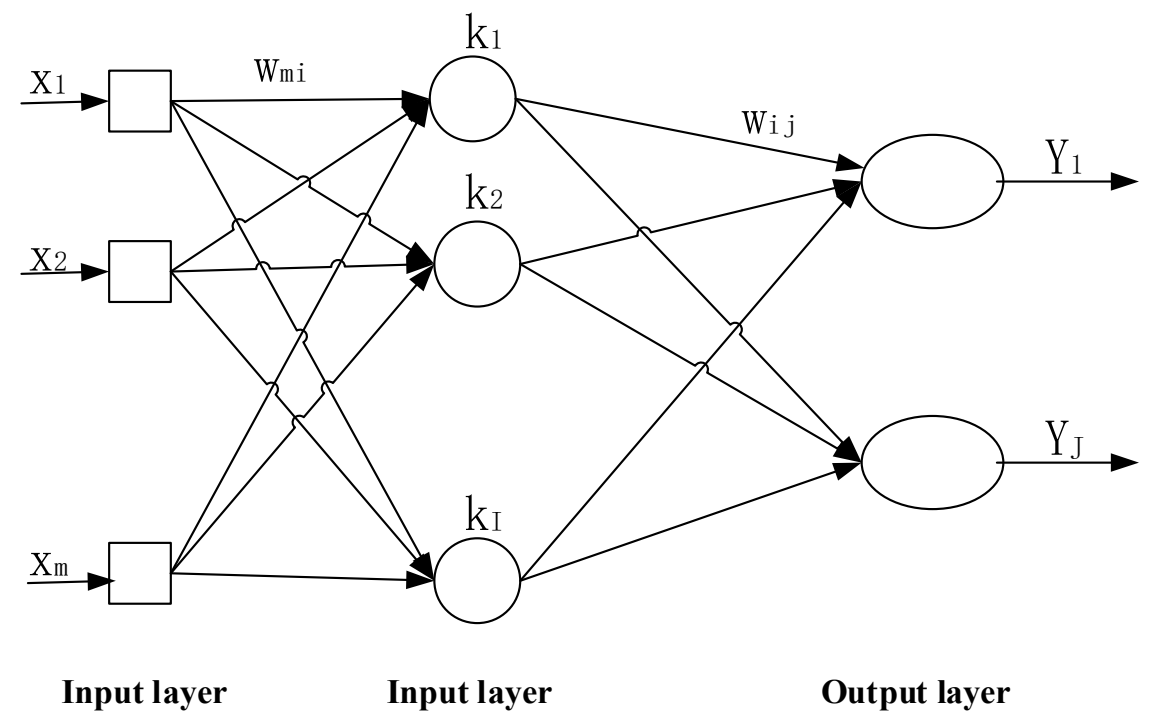

Figure 2. Three-layer model of the Back Propagation neural network.

The figure displays a typical model structure of a three-layer BP neural network, where $M, I$, and $J$ represent the number of neurons in the input, hidden, and output layers, respectively. Other terms are defined as follows:

$X_{m}=m$ neuron in the input layer

$K_{i}=i$ neuron in the hidden layer

$Y_{j}=j$ neuron in the output layer

$W_{m i}=$ connection weight from $X_{m}$ to $K_{i}$

$W_{i j}=$ connection weight from $K_{i}$ to $Y_{j}$ 
From the abovementioned network structure, the input of the neural network is an input quantity of length $M$, which is $X_{1} \sim X_{m}$; the output is $Y_{1} \sim Y_{j}$, and the length is $J$. At this point, we use $U$ and $V$ to respectively indicate the input and output of each layer. For example, $U_{I}^{1}$ represents the input of the first neuron in the $I$ layer.

The actual output of the BP neural network is $Y(n)=\left[v_{J}^{1}, v_{J}^{2}, \cdots v_{J}^{J}\right]$.

The expected output value of the BP neural network is $d(n)=\left[d_{1}, d_{2} \cdots d_{J}\right]$.

\subsection{Implicit Layer Transfer Function and Selection of Training Function}

The transfer function of the BP neural network hidden layer is also called the excitation function, which can complete the information transfer from the input layer to the hidden layer and from the hidden layer to the output layer. The transfer function of the BP neural network must be differentiable, and a sigmoid or a linear function is generally selected as the transfer function. The output curve of the function has obvious biological neuronal characteristics because the characteristics of the sigmoid function are obvious; it is thus a good representation of the actual output form of the neuron. The sigmoid, log-sigmoid, and tan-sigmoid functions can be used depending on whether or not the output values of different research models contain negative values. In this 3PL perspective, the output value of the research model of the guaranteed risk measurement of confirming warehouse financing is positive. Thus, we select the logarithmic function as the transfer function. A simple log-sigmoid function can be determined using the following:

$$
f(x)=\frac{1}{1+e^{-x}}
$$

Among them, the value is taken in the whole real number field, which is between $[0,1]$.

The sigmoid function is a smooth curve function that is more accurate and fault tolerant than the classified linear functions. When selecting the transfer function from the hidden layer to the output layer, the pure linear transfer function purelin is also used as the excitation function.

The most common training functions in the existing MATLAB toolbox are trainlm, traingdx, traingdm, traingd, and other function types. Each training function has its characteristics and is suitable for different training models. The trainlm function is calculated using the least squares calculation method, and the convergence speed is slow. The gradient descent method selected by the traingd function is trained. Although the rate of decline is too fast, the stability is poor. Conversely, the improved function traingdx uses the gradient descent momentum method. This function adds a momentum term as a damping term on the basis of the original function to reduce volatility during descent. The improved traingdm function is also improved in the original function algorithm, which achieves increased training precision and fast convergence. We select traingd and improved traingdx and traingm as training functions. In contrast, the convergence speed, error, and volatility optimal function are determined as the training functions of the model.

\section{Empirical Analysis}

This work selects relevant data from 24 groups of enterprises engaged in confirmed warehouse financing of the ZY Logistics Company as the research sample. Data are derived from the annual report of the enterprises and the Wind information database. Training and simulation are carried out for confirming warehouse financing of ZY Logistics. The index system for measuring the risks of confirming warehouse financing contains qualitative and quantitative indicators due to the established 3PL perspective [42]. Therefore, the qualitative indicators are assigned, and the quantitative indicators are based on the actual data collected. 


\subsection{Collection of Sample Data}

1. Pledge Risk

Price stability (NW1): Price stability is influenced by the variety of pledges and changes in market supply and demand [43] and is expressed as the volatility of the product price. When price volatility is less than $5 \%$, the pledge price stability is considered strong with a value of 3 . When price volatility is $5 \%-10 \%$, the pledge price stability is general with a value of 2 . Lastly, when price volatility is greater than $10 \%$, the pledge price stability is poor with a value of 1 .

Legality (NW2): According to the signed confirming warehouse financing contract, we determine whether or not the pledge is legal. If the 3PL and financial institution determine that the pledge is legal, then the pledge is legally strong and takes a value of 3. If the financial institution and 3PL do not clearly state the legal status of the pledge, then the legality of the pledge is generally defined and takes a value of 2 . If the pledge provided by the financing enterprise has obvious illegality, then the pledge is considered to have a low level of legality and takes a value of 1 .

Liquidity (NW3): The liquidity of pledges is affected by market demand, market prices, and the substitutability of the collateral. After a comprehensive analysis of various influencing factors, we find that if the pledge has strong liquidity, it takes a value of 3 . If the pledge has general liquidity, then it takes a value of 2 . If the pledge has weak liquidity, then it takes a value of 1.

\section{Credit Risk of Financing Companies}

Performance ability (NN1): It is a quantitative indicator measured by the company's compliance rate as follows:

$$
\eta=\frac{F-M}{F} \times 100 \%
$$

where $F$ is the total number of annual contracts of the enterprise and $M$ denotes the number of contracts by default.

Continuing ability (NN2): If the company has been in business for more than five years, then we assume that the company's ability to sustain its operations is strong and takes a value of 3 . If the company is operating for three to five years, then we assign a value of 2 for its ability to continue operations. If the company has been operating for less than three years, it takes a value of 1 , which indicates poor performance.

Profitability (NN3): This term pertains to the profitability of financing companies. The study uses quantitative indicators for the return of assets of enterprises [44].

$$
\frac{\text { Net Income }}{\text { Total Assets }} \times 100 \%
$$

Solvency (NN4): The solvency of enterprises is a quantitative indicator expressed by the asset liability ratio of financing companies [45].

$$
\frac{\text { Total Assets }}{\text { Liability }} \times 100 \%
$$

\section{Internal Management Risk}

Pledge assessment risk (NP1): We stipulate that if the evaluation price of the pledge is lower than the market value, then the pledge is well evaluated and takes a value of 3 . If the assessed value of the pledge is equal to the market value, then the pledge is considered normal and takes a value of 2. Lastly, if the pledge evaluation is higher than the market value, then the pledge evaluation is poor and takes a value of 1 . 
Regulatory system normative (NP2): If the enterprise has a documented implementation of a supervision program for supply chain finance, then the regulatory system is standardized and takes a value of 3 . If an enterprise has an unwritten regulatory system, then its regulatory system is generally normative and takes a value of 2 . If the enterprise does not have a regulatory system for supply chain finance, then the normativeness is considered poor and takes a value of 1 .

Inventory risk warning (NP3): If the enterprise sets a safety stock warning for the pledge with special personnel engaged in inventory risk processing, it takes a value of 3 . If the enterprise does not set a safety stock warning, then the inventory risk is high and takes a value of 1 . The value between the two is 2 .

Operational risk (NP4): If confirming warehouse financing is strictly in accordance with the provisions of the contract, then no deviation will occur amid the operation. This condition indicates that the operational risk is low and takes a value of 3 . If confirming warehouse financing completely deviates from the contract and operates independently, then the operational risk is considered large and takes a value of 1 . If the operational risk is between the two levels, then it takes a value of 2 .

Organizational rationality (NP5): If the company has accordingly set up a department for supply chain finance with a clear division of labor, then the organization is reasonable and takes a value of 3 . If the enterprise has formed a department for supply chain finance without a clear division of labor and system, then the organization is generally reasonable and takes a value of 2 . If the company does not have an independent business unit for supply chain finance, then the organization is not highly reasonable and takes a value of 1 .

\section{Contractual Legal Risk}

Contract standardization (NR1): If a standard written contract exists in the business model of the confirming warehouse and does not require revision and supplementation, then the standardization of the contract is high and takes a value of 3 . If a standard contract exists but needs modification and supplementation according to specific circumstances, then the standardization degree of the contract is low and takes a value of 2 . In the absence of a standard contract, its standardization is considered low and takes a value of 1 .

Contractual liability risk (NR2): If the contract for confirming warehouse financing has a clear division of responsibilities among the three parties, then the agreed liability risk is low and takes a value of 3. If the business contract has a clear division in terms of responsibility among the three parties with certain ambiguous areas, then the agreed liability risk is general and takes a value of 2 . If the contract does not have a significant division of risk, then the risk is high and takes a value of 1 .

Legal policy risk (NR3) [46]: If the local government imposes management regulations and measures for supply chain finance and both enterprises comply with corporate and contract laws, then the legal policy risk is low and takes a value of 3 . If the local government has no relevant laws, but the enterprises are in compliance with contract and enterprise laws, then the legal policy risks are general and takes a value of 2 . If the local government is undergoing war or financial crisis and economic and political instability, then the legal policy risks are high and takes a value of 1 .

3PL too much responsibility (NR4): If the logistics enterprise undertakes a number of businesses, such as supervision, transportation, and pledge evaluation, then it bears excessive responsibility and takes a value of 3 . If the logistics enterprise only bears its internal responsibility, then it bears minimal responsibility and takes a value of 1 . If it is neither of the two scenarios, then it takes a value of 2 .

In this work, the following 24 sets of sample data are obtained through data search and analysis, where D represents the risk level of each supply chain finance business. We obtained the data according to the Duffel method. Sample data is shown in Table 7. 
Table 7. Panel data.

\begin{tabular}{|c|c|c|c|c|c|c|c|c|c|c|c|c|c|c|c|c|c|c|c|c|c|c|c|c|}
\hline Item & $\begin{array}{c}\text { Data } \\
1 \\
\end{array}$ & $\begin{array}{c}\text { Data } \\
2 \\
\end{array}$ & $\begin{array}{c}\text { Data } \\
3 \\
\end{array}$ & $\begin{array}{c}\text { Data } \\
4 \\
\end{array}$ & $\begin{array}{c}\text { Data } \\
5 \\
\end{array}$ & $\begin{array}{c}\text { Data } \\
6 \\
\end{array}$ & $\begin{array}{c}\text { Data } \\
7 \\
\end{array}$ & $\begin{array}{c}\text { Data } \\
8\end{array}$ & $\begin{array}{c}\text { Data } \\
9 \\
\end{array}$ & $\begin{array}{c}\text { Data } \\
10\end{array}$ & $\begin{array}{c}\text { Data } \\
11\end{array}$ & $\begin{array}{c}\text { Data } \\
12\end{array}$ & $\begin{array}{c}\text { Data } \\
13 \\
\end{array}$ & $\begin{array}{c}\text { Data } \\
14\end{array}$ & $\begin{array}{c}\text { Data } \\
15\end{array}$ & $\begin{array}{c}\text { Data } \\
16\end{array}$ & $\begin{array}{c}\text { Data } \\
17\end{array}$ & $\begin{array}{c}\text { Data } \\
18\end{array}$ & $\begin{array}{c}\text { Data } \\
19\end{array}$ & $\begin{array}{c}\text { Data } \\
20\end{array}$ & $\begin{array}{c}\text { Data } \\
21\end{array}$ & $\begin{array}{c}\text { Data } \\
22\end{array}$ & $\begin{array}{c}\text { Data } \\
23\end{array}$ & $\begin{array}{c}\text { Data } \\
24\end{array}$ \\
\hline NW1 & 3 & 2 & 2 & 3 & 2 & 2 & 2 & 3 & 1 & 2 & 3 & 3 & 3 & 3 & 2 & 2 & 3 & 3 & 3 & 2 & 1 & 3 & 2 & 3 \\
\hline NW2 & 3 & 3 & 3 & 2 & 3 & 2 & 3 & 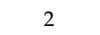 & 2 & 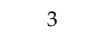 & 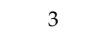 & 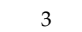 & 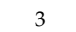 & 0 & 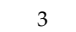 & 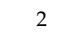 & 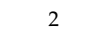 & 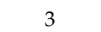 & 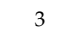 & 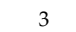 & 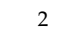 & 3 & 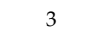 & 3 \\
\hline NW3 & 3 & 3 & 2 & 3 & 3 & 3 & 3 & 3 & 3 & 3 & 2 & 3 & 2 & 3 & 3 & 3 & 3 & 2 & 3 & 3 & 3 & 2 & 3 & 2 \\
\hline NN1 & $100 \%$ & $100 \%$ & $95 \%$ & $90 \%$ & $100 \%$ & $90 \%$ & $100 \%$ & $100 \%$ & $90 \%$ & $90 \%$ & $100 \%$ & $100 \%$ & $100 \%$ & $100 \%$ & $90 \%$ & $100 \%$ & $100 \%$ & $100 \%$ & $100 \%$ & $90 \%$ & $80 \%$ & $100 \%$ & $100 \%$ & $90 \%$ \\
\hline NN2 & 3 & 3 & 3 & 3 & 2 & 2 & 3 & 2 & 3 & 2 & 1 & 2 & 3 & 3 & 3 & 2 & 3 & 3 & 3 & 2 & 2 & 3 & 3 & 3 \\
\hline NN3 & $4.7 \%$ & $6.5 \%$ & $5.3 \%$ & $5.7 \%$ & $8.6 \%$ & $9.7 \%$ & $6.5 \%$ & $10.3 \%$ & $8.9 \%$ & $9.3 \%$ & $8.8 \%$ & $6.9 \%$ & $5.3 \%$ & $6.5 \%$ & $4.7 \%$ & $5.5 \%$ & $11.0 \%$ & $6.8 \%$ & $8.0 \%$ & $7.0 \%$ & $6.5 \%$ & $4.3 \%$ & $9.9 \%$ & $11.0 \%$ \\
\hline NN4 & $59.5 \%$ & $63.0 \%$ & $65.0 \%$ & $55.5 \%$ & $62.3 \%$ & $68.2 \%$ & $54.7 \%$ & $63.0 \%$ & $72.5 \%$ & $49.8 \%$ & $53.6 \%$ & $63.5 \%$ & $63.5 \%$ & $58.5 \%$ & $55.0 \%$ & $63.5 \%$ & $71.0 \%$ & $48.0 \%$ & $71.3 \%$ & $65.0 \%$ & $44.5 \%$ & $53.5 \%$ & $62.5 \%$ & $54.5 \%$ \\
\hline NP1 & 2 & 3 & 3 & 2 & 3 & 2 & 3 & 3 & 3 & 3 & 3 & 2 & 2 & 3 & 3 & 2 & 3 & 3 & 3 & 3 & 2 & 3 & 3 & 3 \\
\hline NP2 & 3 & 3 & 3 & 3 & 3 & 3 & 3 & 2 & 2 & 3 & 2 & 2 & 3 & 3 & 2 & 3 & 2 & 3 & 3 & 2 & 2 & 2 & 3 & 3 \\
\hline NP3 & 3 & 3 & 2 & 3 & 3 & 2 & 3 & 3 & 3 & 2 & 3 & 2 & 3 & 3 & 2 & 2 & 3 & 3 & 3 & 3 & 2 & 3 & 2 & 3 \\
\hline NP4 & 3 & 3 & 3 & 2 & 3 & 2 & 3 & 2 & 3 & 3 & 3 & 3 & 3 & 3 & 3 & 3 & 3 & 3 & 2 & 2 & 3 & 3 & 3 & 3 \\
\hline NP5 & 3 & 2 & 3 & 2 & 3 & 3 & 3 & 3 & 2 & 3 & 3 & 3 & 3 & 3 & 1 & 2 & 3 & 2 & 3 & 1 & 1 & 3 & 2 & 3 \\
\hline NR1 & 3 & 3 & 3 & 3 & 2 & 3 & 1 & 3 & 3 & 3 & 2 & 3 & 3 & 2 & 2 & 2 & 3 & 2 & 2 & 3 & 3 & 2 & 3 & 3 \\
\hline NR2 & 2 & 3 & 1 & 3 & 3 & 2 & 3 & 3 & 2 & 1 & 3 & 3 & 2 & 3 & 2 & 3 & 2 & 3 & 2 & 1 & 3 & 2 & 3 & 2 \\
\hline NR3 & 2 & 2 & 2 & 2 & 3 & 3 & 3 & 2 & 3 & 3 & 3 & 2 & 3 & 3 & 3 & 3 & 2 & 2 & 3 & 3 & 3 & 1 & 2 & 3 \\
\hline NR4 & 3 & 3 & 3 & 2 & 3 & 2 & 3 & 3 & 1 & 3 & 3 & 2 & 3 & 2 & 2 & 2 & 2 & 2 & 2 & 3 & 3 & 1 & 2 & 3 \\
\hline $\begin{array}{c}\text { Risk } \\
\text { level D }\end{array}$ & Low & Low & High & High & Low & High & Low & Medium & High & Medium & Medium & High & Low & Low & High & High & Medium & Medium & Low & High & High & High & Medium & Low \\
\hline
\end{tabular}




\subsection{Processing of Sample Data}

The metrics of each index differs because the sample data contain qualitative and quantitative indicators. Therefore, learning and training in the BP neural network cannot be performed, and the sample data should be further processed. The sample data for the general BP neural network are normalized, that is, all sample data are uniformly converted into a dimensionless index in $[0,1]$. In addition, we normalize the sample data as follows:

$$
\overline{x_{i}}=\frac{x_{i}-x_{\min }}{x_{\max }-x_{\min }}
$$

where $x_{i}$ represents the input and output variables and $x_{\max }$ and $x_{\min }$ denote the minimum and maximum values in the sample data set, respectively. The sample data are normalized using the maximum and minimum methods. Table 8 provides the processing results. 
Table 8. Sample data after normalization.

\begin{tabular}{|c|c|c|c|c|c|c|c|c|c|c|c|c|c|c|c|c|c|c|c|c|c|c|c|c|}
\hline Item & $\begin{array}{c}\text { Data } \\
1\end{array}$ & $\begin{array}{c}\text { Data } \\
2\end{array}$ & $\begin{array}{c}\text { Data } \\
3\end{array}$ & $\begin{array}{c}\text { Data } \\
4\end{array}$ & $\begin{array}{c}\text { Data } \\
5\end{array}$ & $\begin{array}{c}\text { Data } \\
6\end{array}$ & $\begin{array}{c}\text { Data } \\
7\end{array}$ & $\begin{array}{c}\text { Data } \\
8\end{array}$ & $\begin{array}{c}\text { Data } \\
9\end{array}$ & $\begin{array}{c}\text { Data } \\
10\end{array}$ & $\begin{array}{c}\text { Data } \\
11\end{array}$ & $\begin{array}{c}\text { Data } \\
12\end{array}$ & $\begin{array}{c}\text { Data } \\
13\end{array}$ & $\begin{array}{c}\text { Data } \\
14\end{array}$ & $\begin{array}{c}\text { Data } \\
15\end{array}$ & $\begin{array}{c}\text { Data } \\
16\end{array}$ & $\begin{array}{c}\text { Data } \\
17\end{array}$ & $\begin{array}{c}\text { Data } \\
18\end{array}$ & $\begin{array}{c}\text { Data } \\
19\end{array}$ & $\begin{array}{c}\text { Data } \\
20\end{array}$ & $\begin{array}{c}\text { Data } \\
21\end{array}$ & $\begin{array}{c}\text { Data } \\
22\end{array}$ & $\begin{array}{c}\text { Data } \\
23\end{array}$ & $\begin{array}{c}\text { Data } \\
24\end{array}$ \\
\hline NW1 & 1.000 & 0.500 & 0.500 & 1.000 & 0.500 & 0.500 & 0.500 & 1.000 & 0.000 & 0.500 & 1.000 & 1.000 & 1.000 & 1.000 & 0.500 & 0.500 & 1.000 & 1.000 & 1.000 & 0.500 & 0.000 & 1.000 & 0.500 & 1.000 \\
\hline NW2 & 1.000 & 1.000 & 1.000 & 0.000 & 1.000 & 0.000 & 1.000 & 0.000 & 0.000 & 1.000 & 1.000 & 1.000 & 1.000 & 1.000 & 1.000 & 0.000 & 0.000 & 1.000 & 1.000 & 1.000 & 0.000 & 1.000 & 1.000 & 1.000 \\
\hline NW3 & 1.000 & 1.000 & 0.000 & 1.000 & 1.000 & 1.000 & 1.000 & 1.000 & 1.000 & 1.000 & 0.000 & 1.000 & 0.000 & 1.000 & 1.000 & 1.000 & 1.000 & 0.000 & 1.000 & 1.000 & 1.000 & 0.000 & 1.000 & 0.000 \\
\hline NN1 & 1.000 & 1.000 & 0.750 & 0.500 & 1.000 & 0.500 & 1.000 & 1.000 & 0.500 & 0.500 & 1.000 & 1.000 & 1.000 & 1.000 & 0.500 & 1.000 & 1.000 & 1.000 & 1.000 & 0.500 & 0.000 & 1.000 & 1.000 & 0.500 \\
\hline NN2 & 1.000 & 1.000 & 1.000 & 1.000 & 0.500 & 0.500 & 1.000 & 0.500 & 1.000 & 0.500 & 0.000 & 0.500 & 1.000 & 1.000 & 1.000 & 0.500 & 1.000 & 1.000 & 1.000 & 0.500 & 0.500 & 1.000 & 1.000 & 1.000 \\
\hline NN3 & 0.060 & 0.328 & 0.149 & 0.209 & 0.642 & 0.806 & 0.328 & 0.896 & 0.687 & 0.746 & 0.672 & 0.388 & 0.149 & 0.328 & 0.060 & 0.179 & 10 & 0.373 & 0.5 & 0.403 & 0.328 & 0.000 & 0.836 & 1.000 \\
\hline NN4 & 0.536 & 0.661 & 0.732 & 0.393 & 0.636 & 0.846 & 0.364 & 0.661 & 1.000 & 0.189 & 0.325 & 0.679 & 0.679 & 0.500 & 0.375 & 0.679 & 0.946 & 0.125 & 0.957 & 0.732 & 0.000 & 0.321 & 0.643 & 0.357 \\
\hline NP1 & 0.000 & 1.000 & 1.000 & 0.000 & 1.000 & 0.000 & 1.000 & 1.000 & 1.000 & 1.000 & 1.000 & 0.000 & 0.000 & 1.000 & 1.000 & 0.000 & 1.000 & 1.000 & 1.000 & 1.000 & 0.000 & 1.000 & 1.000 & 1.000 \\
\hline NP2 & 1.000 & 1.000 & 1.000 & 1.000 & 1.000 & 1.000 & 1.000 & 0.000 & 0.000 & 1.000 & 0.000 & 0.000 & 1.000 & 1.000 & 0.000 & 1.000 & 0.000 & 1.000 & 1.000 & 0.000 & 0.000 & 0.000 & 1.000 & 1.000 \\
\hline NP3 & 1.000 & 1.000 & 0.000 & 1.000 & 1.000 & 0.000 & 1.000 & 1.000 & 1.000 & 0.000 & $\begin{array}{l}1.000 \\
\text { S }\end{array}$ & 0.000 & 1.000 & 1.000 & 0.000 & 0.000 & 1.000 & 1.000 & 1.000 & 1.000 & 0.000 & 1.000 & 0.000 & 1.000 \\
\hline NP4 & 1.000 & 1.000 & 1.000 & 0.000 & 1.000 & 0.000 & 1.000 & 0.000 & 1.000 & 1.000 & 1.000 & 1.000 & 1.000 & & 1.000 & 1000 & 1.000 & 1.000 & & & 1.000 & & & 1.000 \\
\hline NP5 & 1.000 & 0.500 & 1.000 & 0.500 & 1.000 & 1.000 & 1.000 & 1.000 & 0.500 & 1.000 & 1.000 & 1.000 & 1.000 & 1.000 & 0.000 & 0.500 & 1.000 & 0.500 & 1.000 & 0.000 & 0.000 & 1.000 & 0.500 & 1.000 \\
\hline NR1 & 1.000 & 1.000 & 1.000 & 1.000 & 0.500 & 1.000 & 0.000 & 1.000 & 1.000 & 1.000 & 0.500 & 1.000 & 1.000 & 0.500 & 0.500 & 0.500 & 1.000 & 0.500 & 0.500 & 1.000 & 1.000 & 0.500 & 1.000 & 1.000 \\
\hline NR2 & 0.500 & 1.000 & 0.000 & 1.000 & 1.000 & 0.500 & 1.000 & 1.000 & 0.500 & 0.000 & 1.000 & 1.000 & 0.500 & 1.000 & 0.500 & 1.000 & 0.500 & 1.000 & 0.500 & 0.000 & 1.000 & 0.500 & 1.000 & 0.500 \\
\hline NR3 & 0.500 & 0.500 & 0.500 & 0.500 & 1.000 & 1.000 & 1.000 & 0.500 & 1.000 & 1.000 & 1.000 & 0.500 & 1.000 & 1.000 & 1.000 & 1.000 & 0.500 & 0.500 & 1.000 & 1.000 & 1.000 & 0.000 & 0.500 & 1.000 \\
\hline NR4 & 1.000 & 1.000 & 1.000 & 0.500 & 1.000 & 0.500 & 1.000 & 1.000 & 0.000 & 1.000 & 1.000 & 0.500 & 1.000 & 0.500 & 0.500 & 0.500 & 0.500 & 0.500 & 0.500 & 1.000 & 1.000 & 0.000 & 0.500 & 1.000 \\
\hline $\begin{array}{l}\text { Target } \\
\text { expectation } \\
Y\end{array}$ & 1 & 1 & 3 & 3 & 1 & 3 & 1 & 2 & 3 & 2 & 2 & 3 & 1 & 1 & 3 & 3 & 2 & 2 & 1 & 3 & 3 & 3 & 2 & 1 \\
\hline
\end{tabular}




\subsection{Training and Testing of BP Neural Network}

1. Determining the Number of Neurons in the Hidden Layer

We establish the risk measurement model of confirming warehouse financing from the 3PL perspective using the BP neural network and MATLAB for training and testing. On the basis of the risk measurement model, the number of input neurons is determined to be 16 . The number of neurons in the output is related to the evaluation results, which are proposed as a risk level and unique. The output values are assigned the following values: high risk $=3$, medium risk $=2$, and low risk $=1$. The number of neurons in the hidden layer is determined using the Equation (1). The number of neurons in the hidden layer is determined to be $5 \sim 15$ given that the numbers of neurons in the input and output layers are 16 and 1 , respectively.

To carry out the training and testing of sample data, we select 24 sets of sample data and utilize 20 of them as training data for the risk measurement model of confirming warehouse financing from the 3PL perspective. The remaining 4 sets of data are used as sample data to verify the authenticity of the training results. We use sets $1-20$ of the sample data as the training data and sets $21-24$ as the test sample data.

Moreover, we design a three-layer BP neural network with the tansig transfer function for the hidden layer, purelin for the output layer, and a hidden layer of neurons of $5 \sim 15$. The training function selects the traingm function; the maximum number of trainings is set to 10,000, and network error is set to 0.001 . At this point, only the error curves of the number of neurons in the hidden layer are selected as 11,12,13, and 14 for comparison.
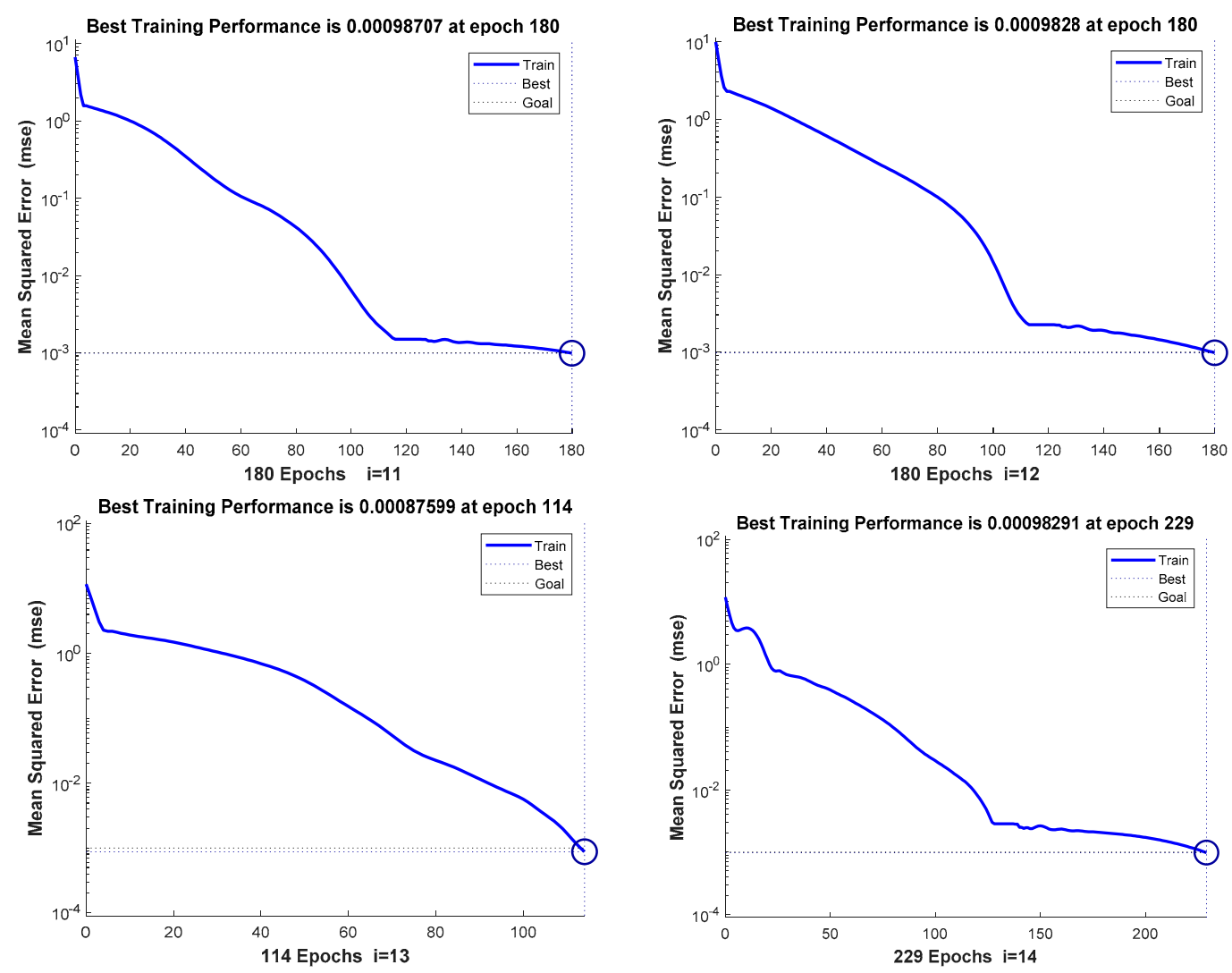

Figure 3. Error plots for different neuron nodes.

Trained as shown in Figure 3, we find that the convergence rate of the BP neural network gradually accelerates with the increase in the number of neurons in the hidden layer. In addition, the training error is gradually reduced. When the number of neuronal nodes reaches 13 , the error reaches a 
minimum value $e=0.00876$. This value is smaller than $e=0.00987$ when the hidden layer node is 12 and increases by up to 14 times when the hidden layer neuron node is $e=0.00983$. From the aspects of convergence speed and descent stability, epoch $=180$ when $i=12$, epoch $=114$ when $i=13$, and epoch $=229$ when $i=14$. After repeated simulation training, the error results of the five trainings are selected for comparison. When the number of neurons in the hidden layer is set to 13, the average error value is small. This finding indicates that this number of neurons is the optimal number of neurons in the hidden layer when the number of neurons is 13 . Table 9 provides the simulation error results.

Table 9. Neuron training error.

\begin{tabular}{ccccccc}
\hline Number of Hidden Neurons & \multicolumn{3}{c}{ Error } & \multicolumn{2}{c}{ AVE } \\
\hline 5 & 0.000977 & 0.000997 & 0.000998 & 0.000995 & 0.000978 & 0.000989 \\
6 & 0.000999 & 0.000989 & 0.000989 & 0.000993 & 0.000997 & 0.000993 \\
7 & 0.001180 & 0.000995 & 0.000997 & 0.000993 & 0.000934 & 0.001020 \\
8 & 0.000991 & 0.000984 & 0.000907 & 0.000823 & 0.000976 & 0.000936 \\
9 & 0.000983 & 0.000995 & 0.000984 & 0.000946 & 0.000992 & 0.000980 \\
10 & 0.000979 & 0.000990 & 0.000976 & 0.000990 & 0.000999 & 0.000987 \\
11 & 0.000990 & 0.000907 & 0.000994 & 0.000986 & 0.000959 & 0.000967 \\
12 & 0.000808 & 0.000932 & 0.000993 & 0.000989 & 0.000935 & 0.000931 \\
13 & 0.000886 & 0.000848 & 0.000924 & 0.000814 & 0.000982 & 0.000891 \\
14 & 0.000999 & 0.000878 & 0.000870 & 0.000856 & 0.000979 & 0.000916 \\
15 & 0.000917 & 0.000987 & 0.000992 & 0.000990 & 0.000979 & 0.000973 \\
\hline
\end{tabular}

\section{Training Function}

When the model selects a neuron node in the hidden layer, the training function used is traingdx, whereas the training of traingdm and traingd is not simulated. In the case of selecting the optimal training function, the selected function should be compared with the optimal training function under common training parameters. Then, the best training function is superior. At this time, the implicit layer transfer function is set to tansig, the output layer transfer function is purein, and the number of neurons in the hidden layer is set to 13 . The maximum number of training times is set to 2000, the network error is set to 0.001 , and traingdm and traingd are selected for the excitation function of the hidden layer due to their slow convergence speed. Figure 4 presents the training results.
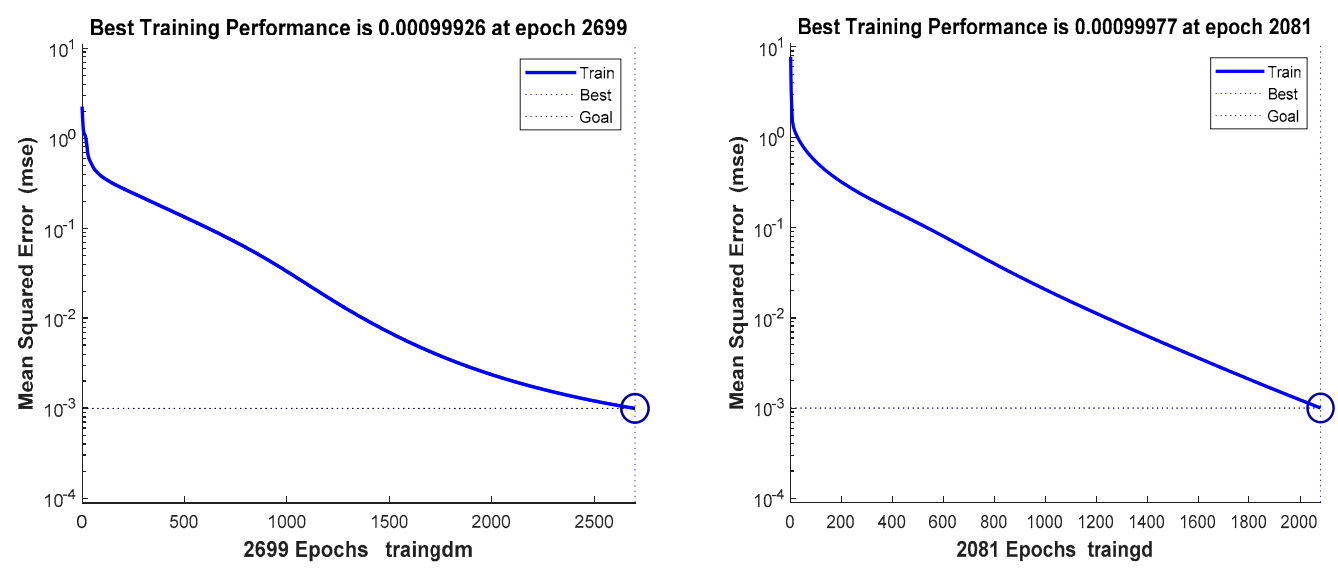

Figure 4. Error plots for training functions.

The training results indicate that when the traingdx function is selected, the network convergence path only reaches 114 steps to reach the expected error value, and error at this time is 0.000876 . Under the same training parameters, the traingdm function must reach epochs $=2699$ upon reaching the training target error value, and epoch $=2018$ when the training function used is traingd. Comparing the error values of the two functions, we find that the error value of the traingdm function is greater 
than the error value of the traingdx. Thus, the traingdx function value is selected as the training function of the hidden layer due to its relatively fast convergence speed and minimal error.

\section{Determining the Learning Rate}

The network learning rate influences the stability and convergence of the BP neural network. To obtain a good network learning rate, we screen the MATLAB network learning rate, which has a default value of 0.01 . Then, we select learning rates of 0.005 and 0.02 to train the model. The training functions of the hidden, input, and output layers select the traingdx, tansig, and purelin functions, respectively. In addition, the number of neurons of the hidden layer is set to 13 with a maximum number of training steps set to 2000 and expected network error value of 0.001 . Figure 5 presents the training results.
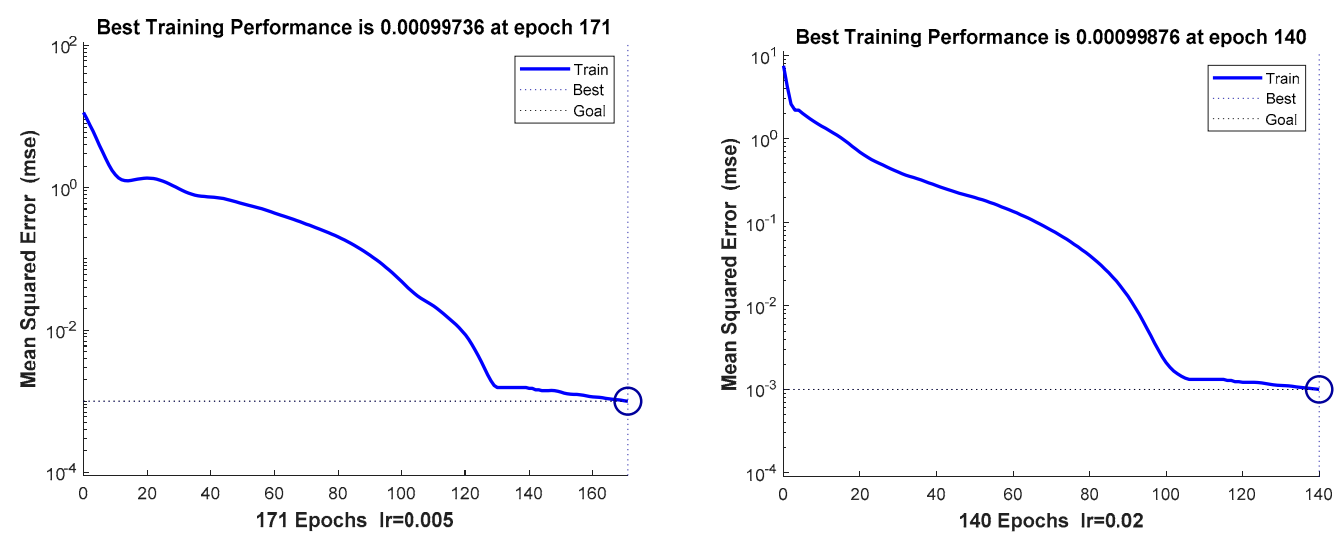

Figure 5. Error plots for the learning rates.

We compare the training values of the three learning rates. At learning rates of $0.005,0.02$, and 0.01 , the error values obtained are $0.000976,0.000987$, and 0.000876 with training frequencies of 171,140 , and 114, respectively. The comparison further indicates that at learning rates of 0.005 and 0.01 , the error and number of training times are greater than the learning rate of 0.01 with a relatively large fluctuation in the error graph. Given a learning rate of 0.01 , the neural network model has good stability. Therefore, the selected learning rate is 0.01 .

\section{Training and Inspection}

Through continual training and testing of the BP network, we establish the various index parameters of the risk measurement model of confirming warehouse financing based on the BP neural network from the 3PL perspective. The number of neurons in the input and output layers is 16 and 1 , respectively, whereas the number of neurons in the hidden layer is 13 . The implicit layer transfer function is tansig, the training function is traveling $\mathrm{dx}$, and the transfer function of the output layer is purelin with the learning rate set to 0.01 and target error value set to 0.001 . Next, we train sample data 1-20 and obtain the output value, as shown in Table 10.

Table 10. Training results of BP neural network.

\begin{tabular}{cccccc}
\hline $\begin{array}{c}\text { Sample } \\
\text { Number }\end{array}$ & $\begin{array}{c}\text { Target } \\
\text { Expectation }\end{array}$ & $\begin{array}{c}\text { Sample } \\
\text { Output Value }\end{array}$ & Absolute Error & $\begin{array}{c}\text { Risk } \\
\text { Classification }\end{array}$ & $\begin{array}{c}\text { Simulation } \\
\text { Classification }\end{array}$ \\
\hline Case 1 & 1 & 0.988185 & -0.011815 & Low risk & Low risk \\
Case 2 & 1 & 1.024202 & 0.024202 & Low risk & Low risk \\
Case 3 & 3 & 3.007828 & 0.007828 & High risk & High risk \\
Case 4 & 3 & 2.984844 & -0.015156 & High risk & High risk \\
Case 5 & 1 & 1.010280 & 0.010280 & Low risk & Low risk \\
\hline
\end{tabular}


Table 10. Cont.

\begin{tabular}{cccccc}
\hline $\begin{array}{c}\text { Sample } \\
\text { Number }\end{array}$ & $\begin{array}{c}\text { Target } \\
\text { Expectation }\end{array}$ & $\begin{array}{c}\text { Sample } \\
\text { Output Value }\end{array}$ & Absolute Error & $\begin{array}{c}\text { Risk } \\
\text { Classification }\end{array}$ & $\begin{array}{c}\text { Simulation } \\
\text { Classification }\end{array}$ \\
\hline Case 6 & 3 & 3.014261 & 0.014261 & High risk & High risk \\
Case 7 & 1 & 0.951964 & -0.048036 & Low risk & Low risk \\
Case 8 & 2 & 2.006169 & 0.006169 & Medium risk & Medium risk \\
Case 9 & 3 & 2.989558 & -0.010442 & High risk & High risk \\
Case 10 & 2 & 1.985808 & -0.014192 & Medium risk & Medium risk \\
Case 11 & 2 & 1.993594 & -0.006406 & Medium risk & Medium risk \\
Case 12 & 3 & 3.003166 & 0.003166 & High risk & High risk \\
Case 13 & 1 & 1.034169 & 0.034169 & Low risk & Low risk \\
Case 14 & 1 & 1.097405 & 0.097405 & Low risk & Low risk \\
Case 15 & 3 & 3.002552 & 0.002552 & High risk & High risk \\
Case 16 & 3 & 2.994301 & -0.005699 & High risk & High risk \\
Case 17 & 2 & 1.994734 & -0.005266 & Medium risk & Medium risk \\
Case 18 & 2 & 1.974535 & -0.025465 & Medium risk & Medium risk \\
Case 19 & 1 & 0.939231 & -0.060769 & Low risk & Low risk \\
Case 20 & 3 & 2.996384 & -0.003616 & High risk & High risk \\
\hline
\end{tabular}

The table shows that the absolute error between the BP neural network training result and expected target value is remarkably small and is within 0.1 . In addition, output value $Y$ can well represent the risk situation of a business, which is consistent with the results obtained by comprehensive evaluation. Among the 20 sets of sample data for training, a majority of the supply chain finance services are in a high-risk state, which accounts for more than $40 \%$ of the overall businesses. This finding serves as a good warning for the risk prevention of $Z Y$ Logistics in supply chain finance. The training results show that the established risk measurement model is characterized by markedly high precision and accuracy and can measure and evaluate the risks of supply chain finance.

The following sets of sample data are used to test the generalizability of the BP neural network model. Results are consistent with predictions, that is, the 3PL perspective of the index system for measuring the risk of confirming warehouse financing is scientific and reasonable. Table 11 provides the results.

Table 11. Test results of BP neural network.

\begin{tabular}{cccccc}
\hline $\begin{array}{c}\text { Sample } \\
\text { Number }\end{array}$ & $\begin{array}{c}\text { Target } \\
\text { Expectation }\end{array}$ & $\begin{array}{c}\text { Sample } \\
\text { Output Value }\end{array}$ & Absolute Error & $\begin{array}{c}\text { Risk } \\
\text { Classification }\end{array}$ & $\begin{array}{c}\text { Simulation } \\
\text { Classification }\end{array}$ \\
\hline Case 21 & 3 & 2.957002 & -0.042998 & High risk & High risk \\
Case 22 & 3 & 2.988898 & -0.011102 & High risk & High risk \\
Case 23 & 2 & 2.020514 & 0.020514 & Medium risk & Medium risk \\
Case 24 & 1 & 1.039448 & 0.039448 & Low risk & Low risk \\
\hline
\end{tabular}

The test errors of the four groups of cases are $-0.042998,-0.011102,0.020514$, and 0.039448 -all of which are small and negligible. The difference between the output value " $Y$ " of the neural network and expected target value is small. In addition, the output result is consistent with the predicted result, which indicates that the proposed risk measurement index system has good evaluation and applicability to the risk of supply chain finance of $Z Y$ Logistics. Through the combination of the actual cases of $\mathrm{ZY}$ Logistics, the BP neural network verified the established risk measurement index system of confirming warehouse financing from the 3PL perspective. The verification results indicate the rationality and applicability of the established indicator system for risk measurement.

\section{Discussion}

According to the training and evaluation of the risk measurement model of confirming warehouse financing from the 3PL perspective, this study found that the confirming warehouse financing of $\mathrm{ZY}$ 
Logistics has a high proportion of high-risk businesses, whereas low-risk businesses account for a relatively small proportion. Among the 24 groups of supply chain finance studied, high-risk businesses reached $41.7 \%$, whereas low-risk businesses accounted for only $29.2 \%$. Although the cited businesses reflect the risk measurement characteristics of the relevant supply chain finance, ZY Logistics should also strengthen its risk prevention measures for its supply chain finance. The 3PL perspective of the index system for measuring the risk of confirming warehouse financing can help node enterprises in the supply chain to conduct a risk assessment of the financial business before conducting supply chain finance. Furthermore, high-risk businesses should be discarded, medium-risk businesses should be controlled, and low-risk businesses should be actively carried out. In this manner, 3PL can be facilitated to carry out supply chain finance in a benign manner and avoid the risks of confirming warehouse financing.

The research results show that the current development of China's supply chain financial business is still in a high-risk period. Enterprises in the supply chain should pay attention to risk prevention when conducting supply chain finance business. The confirmation warehouse finance has special characteristics due to the existence of the reverse repurchase link, and increases the risk commitment of the core enterprise in a certain level. The early research on supply chain financial risk mostly settled in "all-industry, multi-model", ignoring the special risks of single mode. This paper analyzes the financing risks of the confirmation warehouse from the perspective of 3PL, making the risk more targeted. Such research is conducive to the risk prevention of third-party logistics companies in the development of logistics and financial services. According to the established risk measurement index system of confirming warehouse financing and research results, the following recommendations are cited for the development of supply chain finance.

(1) Strengthen the Regulatory Review of Pledges

From the perspective of the risk measurement indicator system, pledge risk is the most direct business risk of supply chain finance faced by enterprises. The results show that under the condition of confirming the financing of ZY Logistics Warehouse, the high-risk business reached $41.7 \%$, and the low-risk business only accounted for $29.2 \%$. In addition, the risk of pledge is significantly higher than the risk of other factors. Although these cases cannot fully summarize the risk level of a company's supply chain finance, it also has certain reference value for this aspect. When selecting pledges, the company should strengthen its screening standards and evaluation criteria, select market demand products with stable market prices and strong liquidity, and avoid seasonal products with high storage conditions and large environmental factors.

\section{(2) Stringent Screening of Cooperative Enterprises}

In supply chain finance, 3PL is the link between financial institutions and financing companies and the bridge for establishing supply chain finance. With the further development of supply chain finance, 3PL plays an increasingly important role and responsibility. In actual operations, the financial indicators of financing enterprises should be strictly controlled, and enterprises with strong profitability, low asset-liability ratio, and long-term operation stability should be selected.

(3) Strengthen and Improve Their Management Level

The pledge and credit risks of financing enterprises are considered external risks. Once a business is established, the internal risks faced by 3PL will gradually be revealed. The regulatory risks of pledges, actual operational risks, and collateral inventory risks should be highly valued by enterprises. Standardizing enterprises is a necessary condition for their long-term development. In actual business operations, enterprises should focus on improving their management level, carry out a reasonable division of labor, set standardized operation procedures, improve staff quality, and formulate a standardized supervision system. 


\section{(4) Focus on Contractual Legal Risk}

Contracts are a direct manifestation of supply chain finance and responsibility distribution. No relevant law has been stipulated in China due to the relatively late development of China's supply chain finance. Several local governments have formulated local laws and regulations to promote the development of local supply chain finance. Therefore, when conducting supply chain finance, a company should promptly and accurately understand and make reasonable use of local policies and regulations for self-protection. Similarly, enterprises should make rational use of China's existing laws, such as enterprise law and contract laws, to protect one's rights when conducting supply chain finance. In dealing with related businesses in other countries, enterprises should be proficient in international conventions and related laws so as to avoid unnecessary predicaments. Moreover, a deep understanding of the laws and policies in foreign countries is required to prevent problems before they occur.

\section{Conclusion and Enlightenment}

Based on the previous studies, the operation process of the confirmation warehouse financing model was analysed. Moreover, financial risks were extracted, and a risk measurement index system was established. Questionnaires are used to obtain data. We analyzed the reliability and validity of data and factor analysis, eliminated unreasonable indicators, and finally established a 3PL confirmation warehouse financing risk measurement index system. Further, the risk measurement model of BP neural network was established. In the empirical analysis part, ZY Logistics Company was selected as the empirical analysis object. A total of 24 sets of confirmed warehouse financing business cases of $Z Y$ Logistics Company were collected. The collected case data were input into the BP neural network risk measurement model for training. Finally, a reliable risk measurement index system was obtained.

This research sought to analyse the risks in the supply chain financial business in a comprehensive, objective, real and scientific way. However, due to the short time of supply chain financial business in China and the lack of market experience, many issues are worthy of in-depth research and discussion. Coupled with my limited thinking ability and practical experience, this study still faces the following problems worthy of improvement and further exploration.

Due to the volatility of the market and the continuous development of the society, the financing model of the confirmation warehouse involved in this study has certain limitations. The business model of supply chain finance will continue to innovate and adapt to the current market environment, followed by the risks existing in the new model. The new risks generated under the new model are one of the directions worth studying.

Although the BP neural network model applied in this study has strong operability and wide adaptability, the requirements for sample data are relatively high. Due to the influence of realistic conditions, the number of sample sizes selected in this study must be supplemented further.

Author Contributions: Conceptualization, Z.W. and Y.W.; methodology, Z.W.; software, Z.W.; validation, Z.W. and Y.W.; formal analysis, Y.W.; investigation, Z.W.; writing—original draft preparation, Z.W.; writing-review and editing, Z.W. and Y.W.

Funding: This research was funded by National Social Science Fund, grant number13YJA790121.

Acknowledgments: In this section you can acknowledge any support given which is not covered by the author contribution or funding sections. This may include administrative and technical support, or donations in kind (e.g., materials used for experiments).

Conflicts of Interest: The funders had no role in the design of the study; in the collection, analyses, or interpretation of data; in the writing of the manuscript, or in the decision to publish the results.

\section{References}

1. Santomero, A.M.; Seater, J.J. Is there an optimal size for the financial sector? J. Bank. Financ. 2000, 24, 945-965. [CrossRef] 
2. Udell, G.F. A more complete conceptual framework for SME finance. J. Bank. Financ. 2006, 30, $2945-2966$.

3. Klapper, L. The role of factoring for financing small and medium enterprises. J. Bank. Financ. 2006, 30, 3111-3130. [CrossRef]

4. Jüttner, U. Supply chain risk management Understanding the business requirements from a practitioner perspective. Int. J. Logist. Manag. 2005, 16, 120-141. [CrossRef]

5. Guillén, G.; Badell, M.; Puigjaner, L. A holistic framework for short-term supply chain management integrating production and corporate financial planning. Int. J. Prod. Econ. 2006, 106, 288-306.

6. Gomm, M.L. Supply chain finance: Applying finance theory to supply chain management to enhance finance in supply chains. Int. J. Logist. Res. Appl. 2010, 13, 133-142. [CrossRef]

7. Gelsomino, L.M.; Mangiaracina, R.; Perego, A.; Tumino, A. Supply chain finance: A literature review. Int. J. Phys. Distrib. Logist. Manag. 2016, 46, 348-366. [CrossRef]

8. Wuttke, D.A.; Blome, C.; Kai, F.; Henke, M. Managing the Innovation Adoption of Supply Chain FinanceEmpirical Evidence from Six European Case Studies. J. Bus. Logist. 2013, 34, 148-166. [CrossRef]

9. Wandfluh, M.; Hofmann, E.; Schoensleben, P. Financing buyer-supplier dyads: An empirical analysis on financial collaboration in the supply chain. Int. J. Logist. Res. Appl. 2016, 19, 200-217. [CrossRef]

10. Atkinson, W. Supply chain finance: The next big opportunity. Supply Chain Manag. Rev. 2008, 12, 57-60.

11. Gobbi, G.; Sette, E. Do Firms Benefit from Concentrating their Borrowing? Evidence from the Great Recession. Rev. Financ 2014, 18, 527-560. [CrossRef]

12. Bing, J.; Seidmann, A. Finance sourcing in a supply chain. Decis. Support Syst. 2014, 58, 15-20.

13. Caniato, F.; Gelsomino, L.M.; Perego, A.; Ronchi, S. Does finance solve the supply chain financing problem? Supply Chain Manag. 2016, 21, 534-549. [CrossRef]

14. Friedman, D.M. Field Warehousing. Columbia Law Rev. 1942, 42, 991-1013. [CrossRef]

15. Dunham, A. Inventory and Accounts Receivable Financing. Harv. Law Rev. 1949, 62, 588. [CrossRef]

16. Burman, R.W. Practical Aspects of Inventory and Receivables Financing. Law Contemp. Probl. 1948, 13, 555-565. [CrossRef]

17. Guerrisi, J. Making Money Move Faster (electronic bill payments). Supply Chain Manag. Rev. 2001, 5, 17-18.

18. Rutberg, S. Financing the Supply Chain by Piggy-backing on the Massive Distribution Clout of United Parcel Service. Secur. Lender 2002, 58, 40-46.

19. Vickery, S.K.; Jayaram, J.; Droge, C.; Calantone, R. The effects of an integrative supply chain strategy on customer service and financial performance: An analysis of direct versus indirect relationships. J. Oper. Manag. 2004, 21, 523-539. [CrossRef]

20. Hofmann, E. Inventory financing in supply chains: A logistics service provider-approach. Int. J. Phys. Distrib. Logist. Manag. 2009, 9, 716-740. [CrossRef]

21. Schaefer, H.; Baumann, S. Managing Behavioural Risks in Logistics-Based Networks-A Project Finance Approach. IUP J. Supply Chain Manag. 2014, 12, 207-227. [CrossRef]

22. Zhong, D.; Sun, B. Research on pricing strategy of 3PL inventory pledge financing service under unified credit mode. J. Hunan Univ. Technol. 2012, 26, 90-95.

23. Coulter, J.; Onumah, G. The role of warehouse receipt systems in enhanced commodity marketing and rural livelihoods in Africa. Food Policy 2002, 27, 319-337. [CrossRef]

24. Schwartz, E.; Smith, J.E. Short-Term Variations and Long-Term Dynamics in Commodity Prices. Manag. Sci. 2000, 46, 893-911. [CrossRef]

25. Chen, J.; Fang, Y.; Xie, F. International Conference on Artificial Intelligence \& Computational Intelligence. In Proceedings of the Research of the Third-party Logistics Enterprise's Warehouse Receipt Pledging Risk Assessment Indicators, Sanya, China, 23-24 October 2010.

26. He, X.; Tang, L. Exploration on Building of Visualization Platform to Innovate Business Operation Pattern of Supply Chain Finance. Phys. Procedia 2012, 33, 1886-1893. [CrossRef]

27. Pellegrino, R.; Costantino, N.; Tauro, D. Supply Chain Finance: A supply chain-oriented perspective to mitigate commodity risk and pricing volatility. J. Purch. Supply Manag. 2019, 25, 118-133. [CrossRef]

28. Leng, K.; Jing, L.; Lin, I.C.; Chang, S.H.; Lam, A. Research on mining collaborative behaviour patterns of dynamic supply chain network from the perspective of big data. Neural Comput. Appl. 2019, 31, 113-121. [CrossRef]

29. Hu, Y.C. Measuring retail company performance using credit scoring techniques. Eur. J. Oper. Res. 2007, 183, 1595-1606. [CrossRef] 
30. Chu, Y. Research on Supply Chain Financial Credit Risk Assessment; Shandong University of Finance and Economics: Shandong, China, 2016.

31. Fan, F.; Shu, G.; Wang, X. Research on Credit Risk Assessment and Risk Management of SMEs under Supply Chain Finance Mode. J. Cent. Univ. Financ. Econ. 2017, 12, 34-43.

32. Zhicheng, G.; Yan, J. Empirical Study on Credit Risk of Listed Companies in Automobile Industry Based on Supply Chain Finance. Logist. Technol. 2017, 2, 136-141.

33. Matoussi, H.; Krichène Abdelmoula, A. Credit-risk evaluation of a Tunisian commercial bank: Logistic regression vs neural network modelling. Account. Manag. Inf. Syst. 2010, 9, 92-119.

34. Bandaly, D.; Satir, A.; Shanker, L. Integrated supply chain risk management via operational methods and financial instruments. Int. J. Prod. Res. 2014, 52, 2007-2025. [CrossRef]

35. Li, Y.; Wu, L. Risk Analysis and Management of Order Financing Business under the Innovation of Logistics Finance. Contemp. Financ. 2008, 2008, 66-70.

36. He, M.; Qian, W. The whole process of logistics financial risk management. Syst. Eng. 2010, $28,30-35$.

37. Yuan, J.; Tang, Q. Logistics financial risk analysis. J. Southeast Univ. (Philos. Soc. Sci. Ed.) 2014, 16, 58-60.

38. Li, L.; Lei, W.; Yu, L. China Control and Decision Conference. In Proceedings of the Research of Financial Risk Warning Model of Listed Companies in the Supply Chain Environment, Taiyuan, China, 23-25 May 2012.

39. Song, W.; Mao, J. Should strengthen the prevention of logistics financial risks. Econ. Asp. 2014, 3, $109-111$.

40. Gorsuch, R.L. Factor analysis. Handb. Psychol. 1983, 27-31.

41. None, A. Handbook of Statistical Analyses Using SAS. Technometrics 2002, 44, 300-301.

42. Dellana, S.; West, D. Survival analysis of supply chain financial risk. J. Risk Financ. 2016, 17, $130-151$. [CrossRef]

43. Mele, F.D.; Bagajewicz, M.; Espuña, A.; Puigjaner, L. Financial risk control in a discrete event supply chain. Comput. Aided Chem. Eng. 2003, 14, 479-484.

44. Hallikas, J.; Lintukangas, K.; Grudinschi, D. Revisiting Supply Chain Risk; Sustainability Risk Management in Supply Chain; Springer: Cham, Switzerland, 2019.

45. Hong, L.C. Supply chain risk's impact on corporate financial performance. Int. J. Oper. Prod. Manag. 2018, 38, 713-731.

46. Lee, S.H.; Wyk, J. National institutions and logistic performance: A path analysis. Serv. Bus. 2015, 9, $733-747$. [CrossRef] 